\title{
Reaching the Urban Poor with Health Interventions: The Case of Hiv Testing In Nairobi Urban Informal Settlements, Kenya
}

\author{
Blessing U. Mberu', Patricia Elungata ${ }^{2}$, Caroline W. Kabiru ${ }^{1}$, and Alex C. Ezeh ${ }^{1}$ \\ ${ }^{1}$ African Population and Health Research Center, Nairobi Kenya \\ ${ }^{2}$ Department of Sociology, McGill University, Montreal, Quebec, Canada \\ bmberu@aphrc.org
}

\begin{abstract}
HIV testing and counseling (HCT) is an entry point to HIV prevention, treatment, and care. In Kenya, national-level data show an astronomical growth in testing. However, national estimates blur sub-group testing differentials and fail to reflect the situation of the most vulnerable groups. We draw on data from 6,035 women and men of reproductive age interviewed in the 2012 Nairobi Cross-sectional Slum Survey and II,909 women and men interviewed in the 2008/09 Kenya Demographic and Health Survey to compare the levels of HIV testing among residents of Nairobi slums and the rest of Nairobi and Kenya. We found that a greater proportion of Nairobi slum dwellers had been tested for HIV compared with residents in other parts of Nairobi and Kenya as a whole. This counter-intuitive finding may be explained by the specific advantage of slum dwellers over the rest of the country in accessing HIV testing services through mobile clinics and research studies. Relatively disadvantaged sub-groups such as women aged 15-19 years and the never married were most likely to be tested in mobile clinics or research studies. Our findings underscore the importance of targeted interventions to reduce inequities in access to HTC services.
\end{abstract}

\section{Résumé}

Le Conseil et le Dépistage Volontaire du VIH (CDV) constituent une voie d'accès à la prévention, au traitement et aux soins $\mathrm{VIH}$. Au Kenya, des données au niveau national montrent une croissance astronomique dans les tests $\mathrm{VIH}$ à travers le pays. Cependant, les estimations nationales brouillent les différentiels entre sous-groupes et ne parviennent pas à refléter la situation des groupes les plus vulnérables. Nous nous sommes appuyé sur des données recueillies auprès de 3892 femmes et 2I 43 hommes en âge de procréer interrogés au cours de l'Enquête Transversale dans les Bidonvilles de Nairobi 2012 et auprès de 11909 femmes et hommes interrogés dans le cadre de l'Enquête Démographique et de Santé 2008/09 du Kenya pour comparer les niveaux de dépistage du VIH chez les habitants des bidonvilles de Nairobi, le reste de Nairobi et les autres parties du Kenya. Nous avons trouvé qu'une plus grande proportion des habitants des bidonvilles de Nairobi a effectué le test VIH comparée aux autres résidents de Nairobi et du Kenya dans sa globalité. Ce résultat inattendu pourrait être expliqué par l'avantage spécifique des habitants des bidonvilles sur le reste du pays dans l'accès aux services de dépistage du VIH par le biais de cliniques mobiles et des études de recherche. Les sousgroupes relativement désavantagés tels que les femmes âgées de 15 à 49 ans et les personnes non mariées avaient plus tendance à effectuer le test $\mathrm{VIH}$ auprès des cliniques mobiles ou pendant les études de recherche. Nos résultats mettent en exergue la nécessité de mettre en place des interventions ciblées en vue de réduire les inégalités dans l'accès aux services de CDV.

\section{Introduction}

Since the first AIDS diagnosis in 1984, HIV/AIDS has remained one of the greatest public health challenges in Kenya. A review of the most recent data underscores the epidemic as a continuing significant public health threat in the country, with an increase in the absolute number of people living with HIV and access gaps for essential prevention, treatment, care and support services (NACC and NASCOP, 20I2). One other key challenge in relation to the infection in Kenya is how urban infection rates have remained higher than rural rates. The HIV prevalence in urban areas in $2012(6.5 \%)$ was higher than that of rural areas (5.1\%) among adults and adolescents aged 1564 years (NASCOP, 2014). Recent evidence showed that HIV prevalence in Kenyan urban areas is principally fueled by very high HIV infection rates in slum areas. A survey of nearly 3,000 men and women found HIV prevalence in Nairobi slums at $12 \%$, compared with $5 \%$ among non-slum urban residents, and $6 \%$ in rural Kenya (Madise et al. 20I2). Although HIV/AIDS continues to pose major public health challenges, Kenya has made significant progress in addressing the epidemic through implementation of relevant policies and programs. 
A comprehensive update indicates that new HIV infections are estimated to have fallen by about 15\% between 2009 and 2013 (NACC, 2014). The country has also embraced the goal of ensuring universal access to HIV prevention, treatment, care and support as well as committed to the vision of zero new HIV infections, zero AIDS deaths, and zero AIDS discrimination (NACC, 20I4).

HIV Testing and Counseling (HCT) is a primary entry point to HIV prevention, treatment, care and support and a cornerstone of Kenya's efforts to address the HIV epidemic (NACC and NASCOP, 2012). The voluntary counseling and testing (VCT) sites rose from only three in 1999 to more than I,000 sites and 4,438 health facilities offering HCT services across the country by the end of 2010 (NACC and NASCOP, 20I2). In 2011, 65\% of all health facilities, including more than $78 \%$ of public sector facilities, were reported to be offering free counseling and testing services. The proportion of adults and adolescents who had ever been tested for HIV reportedly increased from $34.3 \%$ in 2007 to $71.3 \%$ in 2012 (NASCOP, 20I4). Kenya has also adopted various community-based approaches to promote knowledge of HIV status including the delivery of testing services in homes and in the workplace, as well as mobile testing services (NACC and NASCOP, 20I2). These nationwide improvements raise critical social policy and program questions in relation to the extent to which they apply to the urban poor and the particular interventions that are effective. These questions build on evidence that existing national estimates do not sufficiently represent the health and livelihoods conditions of the urban poor, who constitute the majority of city dwellers, due to limited coverage of slums in nationally-representative sample surveys (APHRC, 20I4). Consequently, national indicators generally blur inter- and intra-sub-group inequities and often lack aggregation at local levels, where the needs are located. Yet, taking stock of whether the urban poor are part of the reported success indicators will require adequate data at local levels. This disaggregation will help implementing agencies and local governments pinpoint priorities, measure progress, and identify interventions that work or otherwise (Satterthwaite, 20I4).

Beyond the challenge of appropriate data, the urban poor constitute a hard-to-reach population, as most of them live in informal settlements or slums with innate structural barriers to access to services (The Rockefeller Foundation, 2015). Further, most of the urban poor living in slums are informal workers and their often poor employment conditions may mean that it is not always possible to provide services at the workplace and their unfavorable working hours may mean that service outlets are closed by the time they seek services (ibid). They are also rarely at home even when home-based services are available to other members of the community (Vlahov et al. 2007). Consequently, the urban poor have higher opportunity cost for seeking care, which may mean the loss of wages or jobs, which in turn leads to lower utilization of preventive services such as immunization, ante-natal care, screening for chronic diseases even when they are available and free (The Rockefeller Foundation, 2015).

In this paper, we use data from the 2012 Nairobi Cross-sectional Slums Survey and the 2008/09 Kenya Demographic and Health Survey to answer two specific questions: Have the urban poor benefited as much as other groups from the progress registered in HIV testing at the national level and what are the correlates of HIV testing status among the urban poor in Nairobi? Answers to these questions remain important in the search for pathways to reduce health inequities and improve HIV prevention outcomes among Kenya's most vulnerable populations.

\section{Data and methods}

The primary data source for this analysis is the 2012 Nairobi Cross-sectional Slum Survey (NCSS 20I2) conducted among a representative sample of all informal settlements in Nairobi by the African Population and Health Research Center (APHRC, 20I4). The survey covered a total of 3,892 women and 2, I43 men aged 15-49 years interviewed from 5,490 slum households. In addition to sociodemographic characteristics of the households and individuals, data on HIV/AIDS testing status were obtained for each individual regardless of where the test was taken. Indicators from these data are compared with indicators from the 2008/09 Kenya Demographic and Health Survey (KDHS), which interviewed 8,444 women (15-49) and 3,465 men (I5-54) (Kenya National Bureau of Statistics (KNBS) and ICF Macro (20|0).

The outcome measures used in this analysis included whether the participant had ever been tested for HIV test and the place where the most recent testing was done. Both measures were selfreported. Place of testing was further categorized into 3 groups: (i) Research study/Mobile clinics; (ii) Health facility/Facility integrated testing centers; and (iii) Voluntary Counseling and Testing (VCT) centers. Age, education, marital status, religion, ethnicity, area of residence (a measure of access to a testing center), HIV/AIDS stigma, HIV/AIDS knowledge, knowledge about maternal to child transmission (MTCT) of HIV, and HIV/AIDS risk perception were other key covariates considered. HIV/AIDS stigma was 
measured using four items that assessed whether the respondent would: buy vegetables from AIDSinfected vendor, care for AIDS-infected family member in household, allow AIDS-infected teacher to continue teaching in school and keep secret status of AIDS-infected family member. An affirmative response to all four items was scored as having no stigma. Comprehensive HIV/AIDS knowledge was defined as a respondent knowledge of at least two HIV prevention methods: limiting number of partners, abstain from sex, and use condoms. To capture the socioeconomic status of the households, an asset index was constructed using principal component analysis (PCA) based on different household assets and amenities. The generated wealth score was grouped into tertiles as a measure of socio-economic status with the first tertile representing the poorest group and the last tertile representing the least poor group.

We analyzed the correlates of ever tested for HIV/AIDS using a particular mode of testing (Mobile/Research Study, Facility Integrated or VCT). We estimated separate regression models for males and females because the options and decisions regarding HIV testing have been shown to differ significantly by gender (Kabiru, Luke et al. 2010, Kabiru, Beguy et al. 20I I, Ziraba, Madise et al. 20I I). We used logistic regression with robust standard errors to estimate the relative risk of testing in mobile clinics/research study vis-à-vis other places of testing. We further estimated multinomial logistic regression models to determine the likelihood of being tested at a particular outlet with private/public health facilities being the reference category since they are the most commonly reported places of testing. The model uses alternative-invariant correlates so the predictors retain the same reference category across the testing options, thus the resulting risk ratios can be compared across models. All regression models were adjusted for area of residence effects, using a fixed effect (fixed effect parameters and constants not shown), and for clustering of responses at a type of testing facility using a generalized estimating equation (GEE). We reported $95 \%$ confidence intervals for all parameters and exact $p$-values from Wald tests of significance for all tests where $p<0.05$ to $p<0.001$. The results of these analyses estimate the cross-sectional association between place of testing, socio-economic status and other covariates. All analyses were based on weighted pooled data and to adjust for nonresponse and over-sampling in some areas, sampling weights were used for both bivariate and multivariate analysis. All computations were done using STATA version 12.1 and the standard errors and corresponding confidence intervals of the estimates were computed using bootstrap approach.

\section{Results}

Figure I summarizes the HIV testing status of Nairobi slum dwellers interviewed during the 2012 NCSS compared with other segments of Kenya's population interviewed in the 2008/09 KDHS. A greater proportion of Nairobi slum dwellers (89\%) had ever been tested for HIV compared with Kenya as a whole (5I\%) and other population segments.

In terms of the facilities where respondents were tested, Figure 2 shows that the largest proportion of respondents in the slums and across the country reported being tested in public and private health facilities. Among men and women tested in the slums, about $54 \%$ were tested in public and private hospitals, including antenatal care settings, $24 \%$ were tested in mobile clinics and research studies, and $21 \%$ were tested in VCT centers. For Nairobi as a whole, $56 \%$ were tested in public and private hospitals, $32 \%$ were tested in VCT centers (the highest proportion of people tested in VCT centers across the country) and only $5 \%$ tested in mobile clinics/research studies. For the whole of Kenya, 74\% were tested in public and private hospitals, 15\% were tested in VCT centers and only $9 \%$ tested in in mobile clinics/research studies. These results show that while slum dwellers are in disadvantage in accessing HIV testing services in private and public health facilities relative to the rest of the country, they had 15 percentage point advantage over the rest of the country and 19 percentage point advantage over the whole of Nairobi in accessing testing through mobile clinics/research studies.

Table I summarizes the characteristics of male and female respondents by their testing status and place of testing (for those who have ever tested). The highest proportions of females that had never been tested for HIV were among those aged I5-19 years (24\%), never married individuals (I7\%), those living in the slums all their lives (15\%) and those who perceived no risk of HIV infection (I I\%). For males, the highest proportions that had never been tested were among those aged $15-19$ years (43\%) and those who had never been married (25\%), and Muslims (34\%). In terms of place of testing, a higher proportion of females than males reported being tested in mobile clinics or as part of a research study. Female respondent who mostly tested in mobile clinics and research studies included those aged 1519 years, never married, who had lived in the slum since birth, and Muslims. Among males, those who 
were likely to report being tested in mobile clinics/research studies were never married, Muslims, and of Luo ethnicity.

Table: Testing Status (\%) and Mode of Testing (\%)_by Demographic and Socioeconomic Characteristics, NCSS2 2012

\begin{tabular}{|c|c|c|c|c|c|c|c|c|c|c|}
\hline & & \multicolumn{4}{|c|}{ Females } & \multicolumn{4}{|c|}{ Males } & \multirow[b]{2}{*}{ Total } \\
\hline & CHARACTERISTICS & $\begin{array}{l}\text { Never } \\
\text { Tested }\end{array}$ & $\begin{array}{l}\text { Integrated } \\
\text { Testing }\end{array}$ & $\begin{array}{l}\text { Mobile } \\
\text { Clinics/ } \\
\text { Research } \\
\text { Study }\end{array}$ & VCT & $\begin{array}{l}\text { Never } \\
\text { Tested }\end{array}$ & $\begin{array}{l}\text { Integrated } \\
\text { Testing }\end{array}$ & $\begin{array}{l}\text { Mobile } \\
\text { Clinics/ } \\
\text { Research } \\
\text { Study }\end{array}$ & VCT & \\
\hline \multirow{7}{*}{ Age (Years) ${ }^{a b}$} & 15-19 (Ref.) & 24.2 & 42.2 & 26.6 & 7.0 & 43.3 & 21.2 & 17.5 & 18.0 & 778 \\
\hline & $20-24$ & 4.7 & 66.3 & 18.7 & 10.3 & 17.6 & 32.3 & 19.1 & 31.1 & 1333 \\
\hline & $25-29$ & 1.4 & 72.2 & 17.7 & 8.6 & 12.2 & 33.0 & 23.3 & 31.5 & 1515 \\
\hline & $30-34$ & 2.6 & 71.4 & 18.3 & 7.7 & 9.1 & 41.9 & 22.8 & 26.2 & 855 \\
\hline & $35-39$ & 3.7 & 63.1 & 24.0 & 9.2 & 10.5 & 44.9 & 21.7 & 22.8 & 601 \\
\hline & $40-44$ & 4.0 & 65.3 & 23.3 & 7.4 & 9.5 & 50.0 & 19.0 & 21.4 & 344 \\
\hline & $45-49$ & 7.6 & 53.8 & 31.8 & 6.8 & 16.3 & 41.8 & 18.4 & 23.5 & 230 \\
\hline \multirow{2}{*}{ Educational Attainment ${ }^{\mathrm{a} b}$} & Primary or Less (Ref.) & 6.9 & 65.2 & 20.8 & 7.1 & 21.0 & 34.0 & 19.6 & 25.4 & 2511 \\
\hline & Secondary Plus & 6.2 & 63.0 & 20.8 & 10.0 & 12.7 & 38.0 & 21.8 & 27.5 & 3145 \\
\hline \multirow{3}{*}{ Marital Status $^{a b}$} & Never Married (Ref.) & 17.0 & 43.5 & 26.3 & 13.2 & 24.6 & 25.5 & 21.5 & 28.4 & 1837 \\
\hline & Married/Living Together & 2.3 & 73.6 & 17.9 & 6.2 & 9.9 & 44.2 & 20.7 & 25.1 & 3373 \\
\hline & Formerly Married & 2.2 & 65.6 & 22.3 & 9.9 & 14.9 & 31.1 & 20.3 & 33.8 & 446 \\
\hline \multirow{5}{*}{ Duration of Stay (Years) ${ }^{a b}$} & $<2$ years (Ref.) & 7.0 & 65.4 & 17.7 & 9.9 & 18.4 & 34.1 & 21.5 & 25.9 & 1999 \\
\hline & 2-4 years & 4.4 & 68.3 & 19.4 & 7.9 & 14.3 & 37.1 & 21.0 & 27.6 & 1408 \\
\hline & 5-7 years & 4.7 & 66.3 & 21.1 & 7.9 & 10.0 & 39.5 & 18.8 & 31.7 & 764 \\
\hline & $8+$ years & 6.5 & 60.5 & 25.1 & 7.9 & 13.7 & 38.9 & 21.6 & 25.8 & 1046 \\
\hline & Since Birth & 15.3 & 47.1 & 30.6 & 7.0 & 23.4 & 34.0 & 20.8 & 21.8 & 439 \\
\hline \multirow{4}{*}{ Religion $^{\mathrm{b}}$} & Catholic (Ref.) & 6.8 & 65.3 & 20.5 & 7.4 & 16.2 & 31.8 & 20.9 & 31.1 & 1498 \\
\hline & Protestant/Other Christian & 6.3 & 63.7 & 20.8 & 9.1 & 14.6 & 39.2 & 20.8 & 25.4 & 3857 \\
\hline & Muslim & 9.9 & 58.6 & 23.4 & 8.1 & 33.8 & 22.5 & 23.9 & 19.7 & 182 \\
\hline & Other Religion & 3.6 & 71.4 & 19.6 & 5.4 & 17.5 & 38.1 & 22.2 & 22.2 & 119 \\
\hline Ethnicity $^{\text {a }}$ & Kamba (Ref.) & 6.9 & 60.1 & 22.7 & 10.3 & 16.2 & 32.8 & 21.3 & 29.7 & 1323 \\
\hline
\end{tabular}


African Population Studies Vol. 30, No.3, 2016

\begin{tabular}{|c|c|c|c|c|c|c|c|c|c|c|}
\hline & Kikuyu & 7.0 & 65.6 & 18.5 & 8.9 & 15.6 & 32.9 & 22.4 & 29.1 & 1234 \\
\hline & Luhya & 6.5 & 64.1 & 22.2 & 7.2 & 16.4 & 41.0 & 16.2 & 26.4 & 1328 \\
\hline & Luo & 5.3 & 66.9 & 20.7 & 7.1 & 13.3 & 37.8 & 25.9 & 23.1 & 859 \\
\hline & Other & 6.7 & 64.7 & 19.2 & 9.4 & 16.6 & 39.8 & 20.9 & 22.6 & 912 \\
\hline \multirow{8}{*}{ Area of Residence (Division) ${ }^{a b}$} & Dagoretti (Ref.) & 6.8 & 68.6 & 20.7 & 3.9 & 14.5 & 49.4 & 13.2 & 23.0 & 780 \\
\hline & Kibera & 4.6 & 59.5 & 28.2 & 7.7 & 14.3 & 45.6 & 19.0 & 21.0 & 795 \\
\hline & Embakasi & 7.2 & 59.6 & 20.9 & 12.3 & 20.0 & 26.7 & 24.9 & 28.4 & 1640 \\
\hline & Makadara & 6.9 & 62.1 & 17.9 & 13.1 & 14.9 & 30.5 & 24.2 & 30.5 & 644 \\
\hline & Central & 5.7 & 56.8 & 28.0 & 9.5 & 14.5 & 37.8 & 22.1 & 25.6 & 436 \\
\hline & Kasarani & 5.5 & 72.7 & 16.8 & 5.0 & 13.7 & 38.4 & 16.8 & 31.1 & 571 \\
\hline & Pumwani & 9.2 & 66.3 & 15.3 & 9.2 & 8.9 & 27.7 & 19.6 & 43.8 & 275 \\
\hline & Westlands & 7.5 & 75.0 & 13.1 & 4.4 & 13.8 & 51.8 & 19.5 & 14.9 & 515 \\
\hline \multirow{3}{*}{$\underset{\mathrm{b}}{\mathrm{H}}$ Household Assets Index (Tertiles) } & Lowest (Ref.) & 5.2 & 64.9 & 20.2 & 9.8 & 18.4 & 33.2 & 22.0 & 26.4 & 1491 \\
\hline & Middle & 6.9 & 66.2 & 20.2 & 6.7 & 15.9 & 39.2 & 17.5 & 27.4 & 1896 \\
\hline & Highest & 7.1 & 62.0 & 21.6 & 9.4 & 13.6 & 36.6 & 23.6 & 26.3 & 2269 \\
\hline \multirow{5}{*}{ Risk of getting HIV/AIDS ${ }^{\text {a }}$} & Small (Ref.) & 3.9 & 65.8 & 20.3 & 10.0 & 12.5 & 34.9 & 21.7 & 30.9 & 2560 \\
\hline & Moderate & 3.2 & 69.7 & 19.7 & 7.3 & 11.4 & 42.1 & 22.9 & 23.6 & 454 \\
\hline & Great & 5.0 & 71.9 & 16.6 & 6.5 & 15.6 & 51.1 & 15.6 & 17.8 & 244 \\
\hline & No Risk At All & 11.3 & 59.3 & 21.9 & 7.5 & 22.8 & 35.1 & 21.5 & 20.5 & 1589 \\
\hline & Don't Know & 5.8 & 63.6 & 21.8 & 8.8 & 23.4 & 43.9 & 14.0 & 18.7 & 809 \\
\hline \multirow{2}{*}{$\begin{array}{l}\text { Comprehensive } \\
\text { Knowledge Index a }\end{array}$} & Not Comprehensive (Ref.) & 9.4 & 63.5 & 18.8 & 8.2 & 20.7 & 35.7 & 22.3 & 21.3 & 2424 \\
\hline & Comprehensive & 4.0 & 64.6 & 22.5 & 8.9 & 13.1 & 37.0 & 20.3 & 29.6 & 3232 \\
\hline \multirow{2}{*}{ HIV/AIDS Stigma Index ${ }^{\text {a }}$} & Stigma (Ref.) & 7.7 & 62.3 & 20.6 & 9.4 & 15.6 & 40.4 & 20.4 & 23.6 & 3582 \\
\hline & No Stigma & 4.8 & 66.7 & 21.1 & 7.4 & 16.2 & 27.7 & 22.4 & 33.7 & 2074 \\
\hline \multirow{2}{*}{ MTCT Knowledge Index ${ }^{\text {a }}$} & Inadequate (Ref.) & 7.5 & 61.9 & 21.4 & 9.2 & 17.1 & 40.8 & 19.8 & 22.4 & 2921 \\
\hline & Adequate & 5.7 & 66.1 & 20.2 & 8.0 & 14.1 & 31.0 & 22.5 & 32.4 & 2735 \\
\hline Total & & 6.5 & 64.1 & 20.8 & 8.6 & 15.8 & 36.5 & 21.0 & 26.7 & 5656 \\
\hline
\end{tabular}

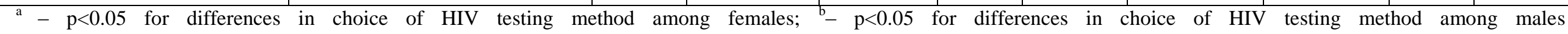


We examined the above relationships in two multivariate models. The first multivariate model compares the correlates of testing in mobile clinics/research studies vis-à-vis testing in all other facilities together (Table 2). We repeated the analysis comparing testing in private and public health facility (the most commonly reported place of testing) vis-àvis those never tested and testing in specific individual outlets using a multinomial logistic regression model. However, to focus on understanding slum residents more likely to use mobile clinics/research studies for testing, the results in Table 3 compare the demographic and socio-economic characteristics of of those who tested in mobile clinics/research studies versus those tested in private and public health facilities (results for all other comparisons are available and can be provided on request).

The logistic regression results summarized in Table 2 show that older females (aged between 20 and 34 years) were about $40 \%$ less likely to receive HIV testing via mobile clinics or research studies compared with those aged between 15 and 19 years. Variation was also observed by duration of stay in the slums. Females who had lived in the slum for 5 years or more and those who had lived in the slum since birth were $50 \%$ and $70 \%$ more likely to have been tested in a mobile clinic or research study respectively compared with those who had lived in the slum for less than 2 years. Across both sexes currently married respondents were less likely to test in a mobile clinics or during a research study compared with their never married counterparts. Females from the Kikuyu ethnic group were 30\% less likely to report testing in mobile clinics or through research studies compared with females from the Kamba ethnic group. Among males, those from the Luo ethnic group were $40 \%$ more likely to report testing in mobile clinics or through research studies than males from the Kamba ethnic group. Females with comprehensive knowledge of HIV were $30 \%$ more likely to report testing in mobile clinics or through research studies compared with those with low knowledge. In contrast, males with comprehensive knowledge of HIV were about $20 \%$ less likely to report being tested in mobile clinics/research studies compared with those without low knowledge.

Table 2: Logistic regression model predicting HIV testing via mobile clinic or research study vis-à-vis all other testing facilities among residents in Nairobi's Informal Settlements, NCSS 2012

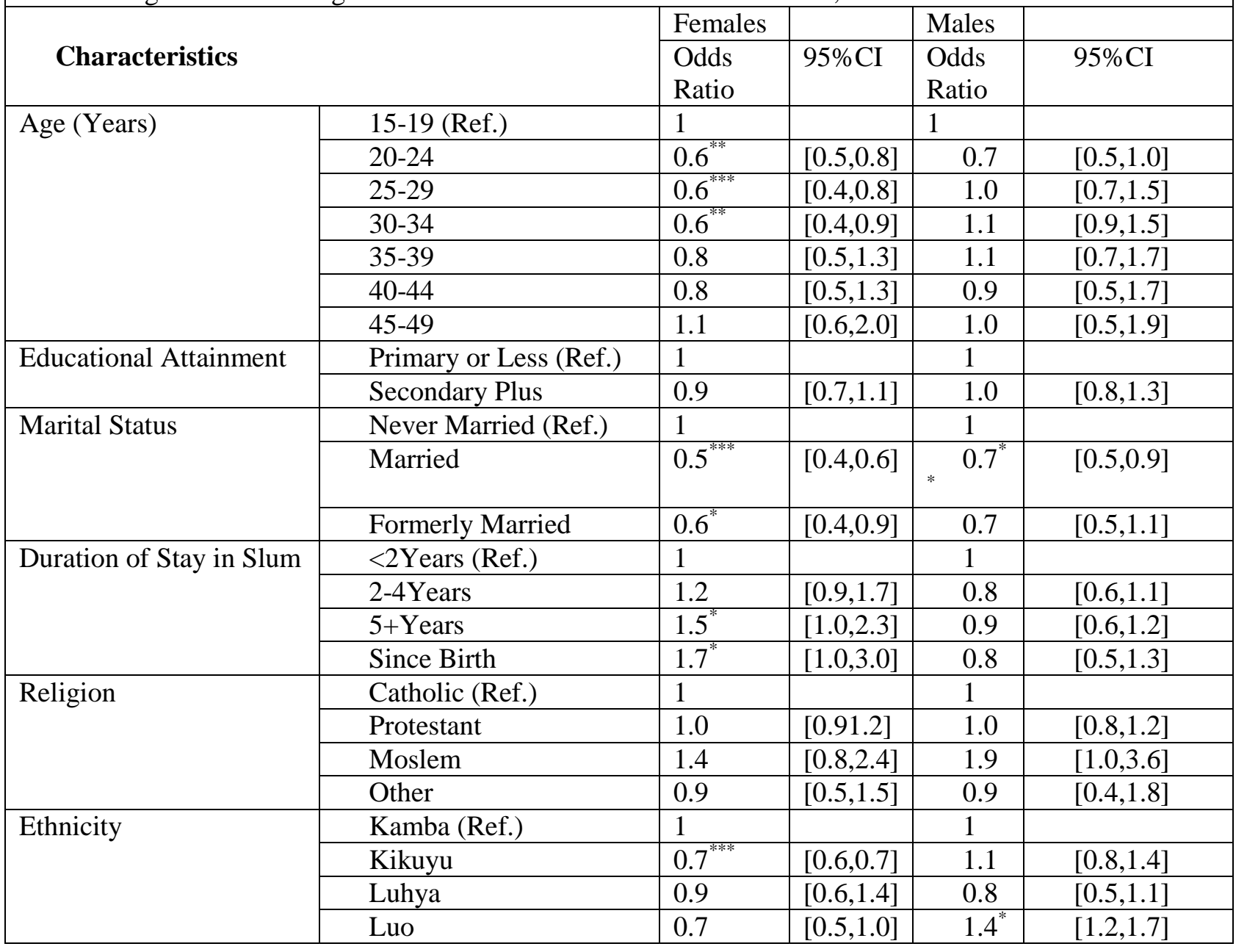




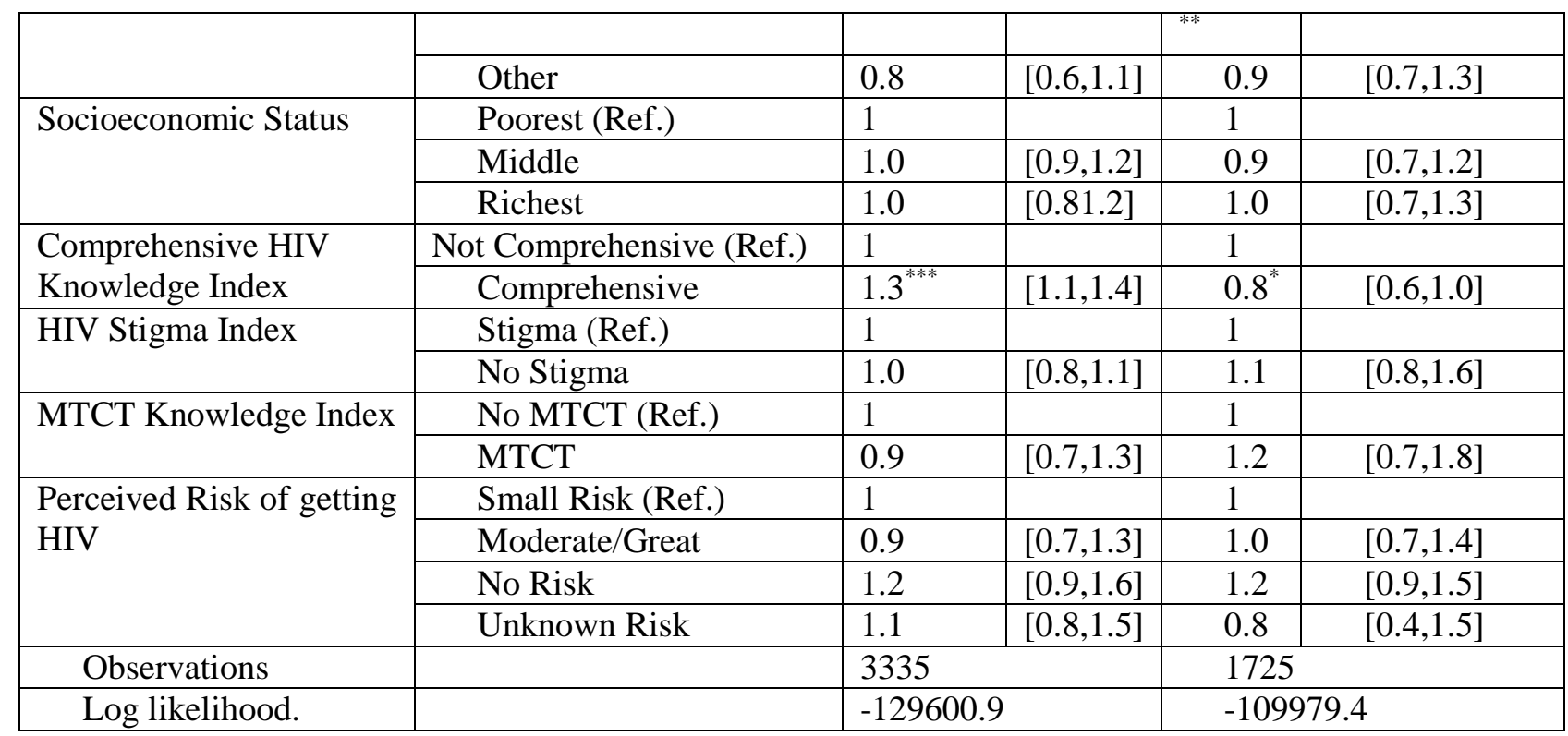

Exponentiated coefficients.

Table 3: Multinomial logistic regression models HIV testing facility by sex, NCSS 2012

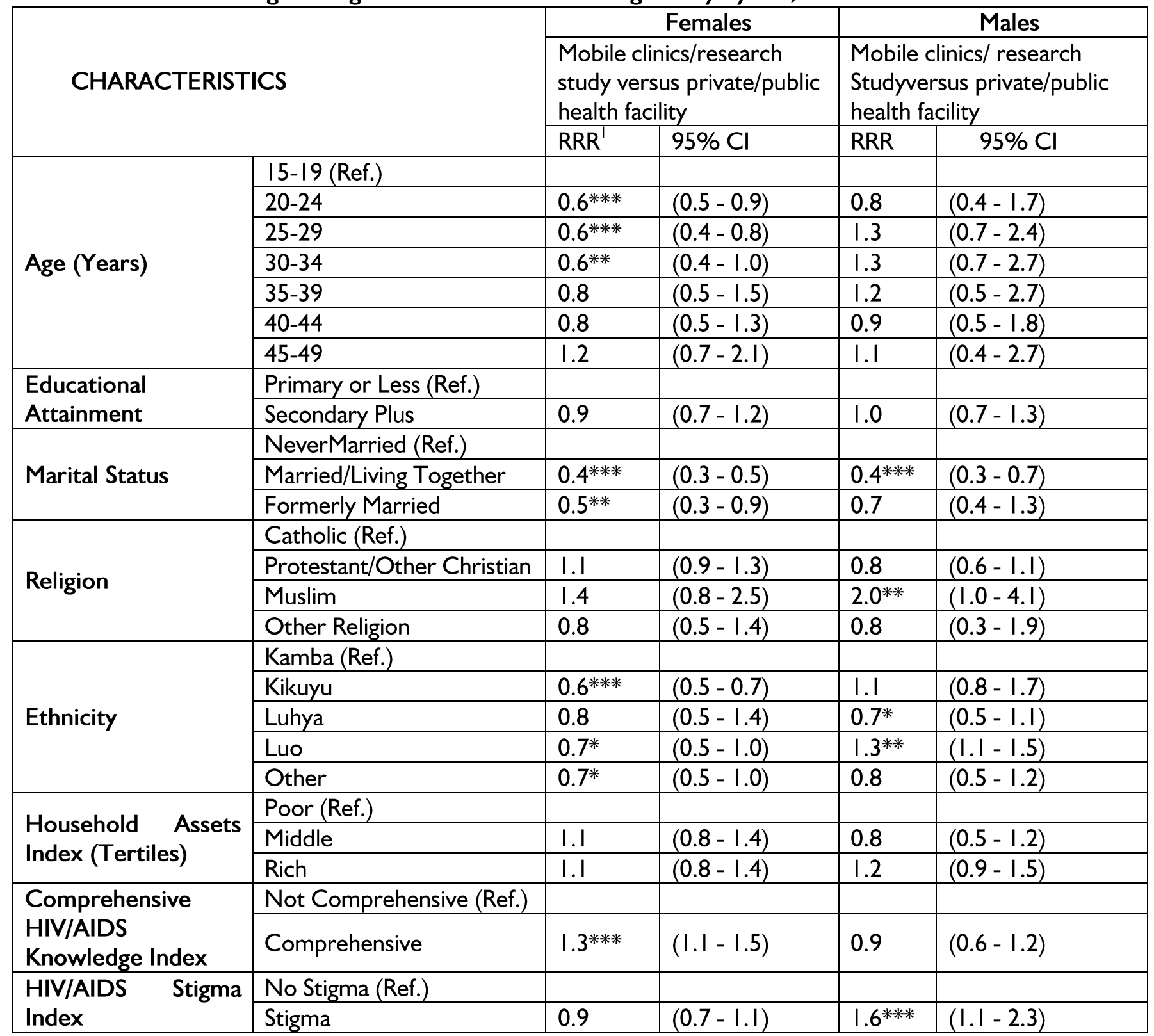




\begin{tabular}{|c|c|c|c|c|c|}
\hline \multirow{2}{*}{$\begin{array}{l}\text { MTCT Knowledge } \\
\text { Index }\end{array}$} & Inadequate MTCT (Ref.) & & & & \\
\hline & MTCT & 0.9 & $(0.7-1.2)$ & $1.5^{*}$ & $(0.9-2.3)$ \\
\hline \multirow{4}{*}{$\begin{array}{l}\text { Risk of } \\
\text { HIV/AIDS }\end{array}$} & Small (Ref.) & & & & \\
\hline & Moderate/Great & 0.9 & $(0.7-1.3)$ & 0.7 & $(0.5-1.2)$ \\
\hline & No Risk at All & 1.2 & $(0.9-1.5)$ & $\mathrm{I}$ & $(0.7-1.4)$ \\
\hline & Don't Know Risk & 1.1 & $(0.8-1.6)$ & 0.5 & $(0.2-1.4)$ \\
\hline \multirow{6}{*}{$\begin{array}{l}\text { Duration of Stay } \\
\text { (Years) }\end{array}$} & $<2$ years (Ref.) & & & & \\
\hline & $2-4$ years & 1.2 & $(0.8-1.6)$ & 0.8 & $(0.6-1.1)$ \\
\hline & $5-7$ years & $1.5 *$ & $(0.9-2.3)$ & 0.9 & $(0.6-1.3)$ \\
\hline & Since Birth & 1.6 & $(0.8-3.0)$ & $0.7^{*}$ & $(0.4-1.0)$ \\
\hline & Constant & $0.7 * *$ & $(0.5-1.0)$ & I.I & $(0.4-2.9)$ \\
\hline & Observations & \multicolumn{2}{|l|}{3,597} & 2,059 & \\
\hline
\end{tabular}

${ }^{1}$ RRR (Relative Risk Ratio).

The results in Table 3 further show that females who were tested in mobile clinics or through research studies were relatively younger (I5-19 years old), never married, from Kamba ethnic group, and had comprehensive HIV/AIDS knowledge. Among males, those who were tested in mobile clinics or though research studies were more likely to be never married, Muslim, of Luo ethnicity, and to have a positive score on the HIV/AIDS stigma index.

\section{Discussion}

In this paper, we assessed and compared the levels and sources of HIV testing services among men and women in Nairobi's slums, the rest of Nairobi and the whole of Kenya. Contrary to the welldocumented disadvantage of urban slum dwellers relative to the rest of the Kenyan population across social, economic and health indicators (APHRC 2002, APHRC 2008), slum dwellers showed remarkable advantage in HIV testing status relative to all other sub-populations across the country. This intriguing but counter-intuitive finding raises important questions on what conferred such an unusual advantage to an otherwise disadvantaged subpopulation, who are generally hard-to-reach even when services are available and free. Our analysis of data from the 2012 NCSS and the 2008/09 KDHS, showed that the usual disadvantage of the urban poor relative to other population sub-groups in accessing HIV testing through both private and public health facilities remains. However, slum dwellers had a 19 percentage point advantage over Nairobi residents as a whole and 15 percentage point advantage over the rest of Kenyan population in access to HIV testing through mobile clinics/research studies. The finding suggests that the generally higher prevalence of HIV testing noted among residents of Nairobi's informal settlements compared with other segments of the population was largely due to accessibility of testing services through mobile clinics and research studies in these settings. The findings highlight the complementary roles of initiatives beyond public facilities and VCT centers in providing services to hard-to-reach groups in informal settlements.

The findings suggest that specific sub-groups in urban slums-such as those who are young and never married—may not be adequately reached by static testing services but may better be served by less conventional service delivery models such as mobile clinics and research studies. Previous studies have highlighted the unique barriers that young people face in accessing health services (Kabiru, Izugbara et al. 2013, Mumah, Kabiru et al. 2014) including fear of stigma, the lack of providers trained to meet young people's unique needs, and inconvenient hours of services in health facilities.

The findings of this paper should be interpreted in light of the following limitations. First, we rely on selfreported data that may be subject to social desirability bias. Second, we were unable to distinguish between respondents who used mobile clinics and those reached through research studies.

\section{Conclusion}

Our results highlight how mobile clinics and targeted research studies serve those least likely to be served by formal testing institutions. The sporadic and nonpermanent nature of mobile clinics most likely creates an enabling opportunity for young men and women to move in anonymously and get tested. As part of the search for intervention that works and pathways to address the challenge of health inequity between slum and non-slum urban dwellers, our analysis identifies the unequivocal importance of public facilities in providing health services for the majority of a country's population, which in the case of Kenya is consistent with national trends and investments. However, we also identified the significant role of non-traditional service delivery models that mediate service access disadvantages of slum and other specific hard to reach sub-groups.

To realize its purpose as a gateway to prevention, treatment, care and support, HIV counseling and 
African Population Studies Vol. 30, No.3, 2016

testing service provision needs to include reliable needed services. Specifically for slum dwellers, our analysis offered insights into service delivery models that work among them. Such interventions, which are convenient and adaptable to specific contexts, may hold the promise of bridging service access and utilization deficits among disadvantaged populations throughout the country.

\section{References}

APHRC (African Population and Health Research Center) (2002). Population and health dynamics in Nairobi's informal settlements: Report of the Nairobi Cross-sectional Slums Survey (NCSS) 2000. Nairobi, APHRC.

APHRC (African Population and Health Research Center) (2008). Policy and program issues emerging from $A P H R C^{\prime}$ 's education research in urban informal settlements of Nairobi, Kenya. Nairobi, APHRC.

APHRC (African Population and Health Research Center) (2014). Population and Health Dynamics in Nairobi's Informal Settlements: Report of the Second Nairobi Cross-sectional Slums Survey (NCSS) 2012. Nairobi, APHRC.

Kabiru, C. W., D. Beguy, J. Crichton and E. Zulu (20II). "HIV/AIDS among youth in urban informal (slum) settlements in Kenya: What are the correlates of and motivations for HIV testing?" BMC Public Health I I ( ): 685.

Kabiru, C. W., C. O. Izugbara and D. Beguy (20I3). "The health and wellbeing of young people in subSaharan Africa: an under-researched area?" BMC Int Health Hum Rights I3: I I.

Kabiru, C. W., N. Luke, C. Izugbara and E. Zulu (20I0). "The correlates of HIV testing and impacts on sexual behavior: evidence from a life history study of young people in Kisumu, Kenya." BMC Public Health IO(I): 4I2: doi:410.1186/I47I2458-I I I0-14 I 2.

Kenya National Bureau of Statistics (KNBS) and ICF Macro (2010). Kenya Demographic and Health Survey 2008-09. Calverton, Maryland, KNBS and ICF Macro.

Madise, J. N., A. K. Ziraba, J. Inungu, S. A. Khamadi, A. Ezeh, E. M. Zulu, J. Kebaso, V. Okoth and M. Mwau (20I2). "Are slum dwellers at heightened risk of HIV infection than other urban residents? Evidence from population-based HIV prevalence surveys in Kenya." Health \& Place 18 (5): II44II 52.

Mumah, J., C. W. Kabiru, C. Mukiira, J. Brinton, M. Mutua, C. Izugbara, H. Birungi and I. Askew (20|4). Unintended pregnancies in Kenya: a country profile [STEP UP Research Report]. mechanisms to link hard-to-reach individuals to Nairobi, African Population and Health Research Center.

NASCOP (National AIDS and STI Control Programme) (20I4). Kenya AIDS Indicator Survey 2012: Final Report. Nairobi, NASCOP June 2014.

NACC (National AIDS Control Council) (2014). Kenya AIDS Response Progress Report 2014. Progress towards Zero. Nairobi, NACC.

NACC (National AIDS Control Counci) and NASCOP (National AIDS/STI Control Programme) (20I2). Kenya AIDS Epidemic Update 2011. Nairobi, Kenya, NACC and NASCOP.

Satterthwaite, D. (20/4). Health in Urban Slums depends on better local data. Paper presented at the International Conference on Urban Health in Manchester, United Kingdom, 5-7 March, 2014.

The Rockefeller Foundation (2015). Insights into urban informal workers and their health

https://assets.rockefellerfoundation.org/app/uploads/2 0 5 I 009 | 22638/Insights-Into-Informal-Workersand-their-Health.pdf

Vlahov D, Freudenberg N, Proietti F, Ompad D, Quinn A, Nandi V and Galea S. (2007). Urban as a determinant of health. Journal of Urban Health, vol. 84, no.3, May 2007

Ziraba, A. K., N. J. Madise, J. K. Kimani, S. Oti, G. Mgomella, M. Matilu and A. Ezeh (20II). "Determinants for HIV testing and counselling in Nairobi urban informal settlements." BMC Public Health II: 663: doi: I0.1 |86/|47|-2458-IIII1663. 


\section{Figures and Tables}

Figure I Percentage of Men and Women Aged I 5 Years and Older Who Have Ever Tested for HIV

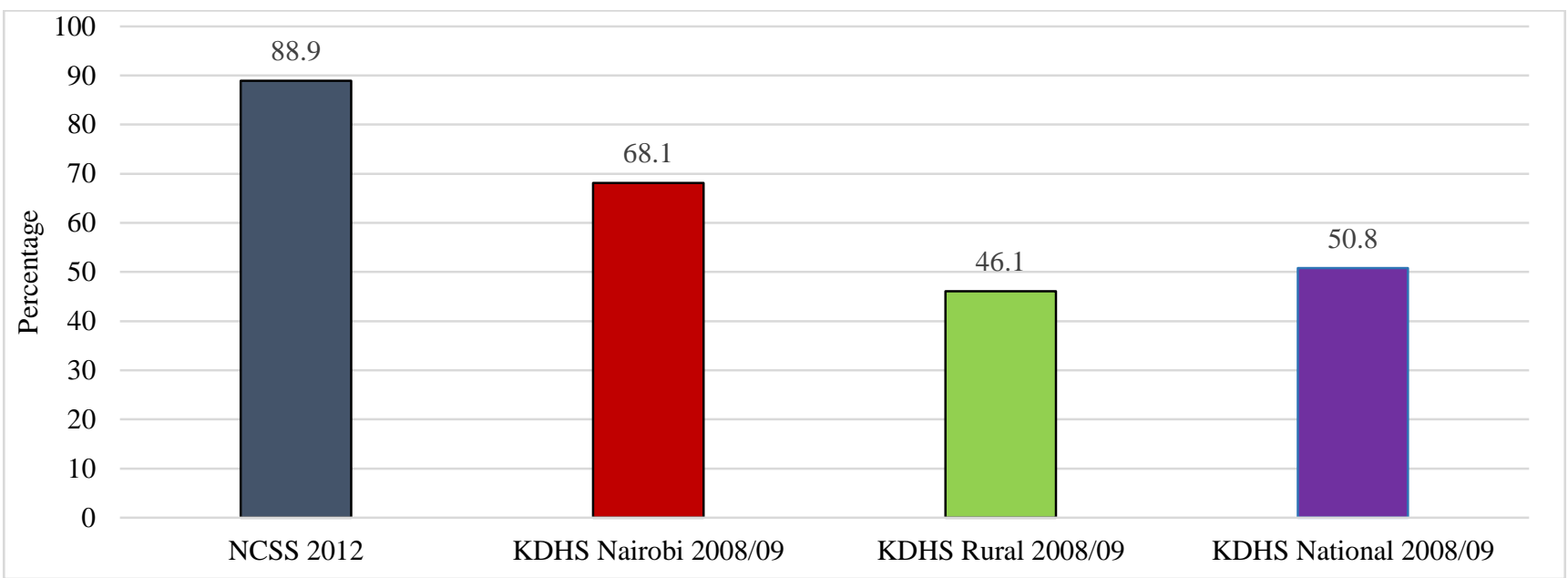

Figure 2 Percentage of Men and Women Receiving HIV Testing Services through Various Outlets

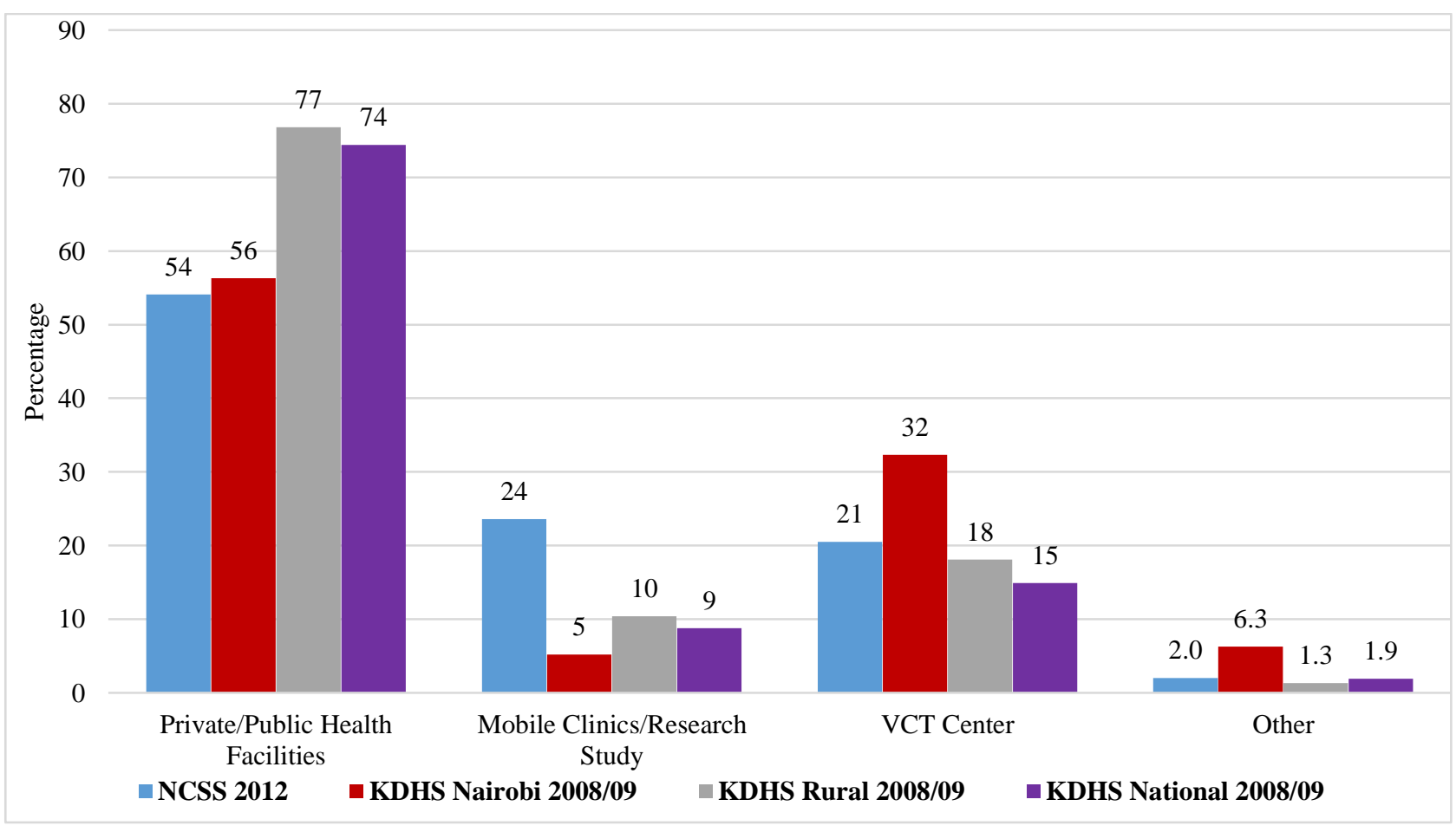

